\title{
Changes in insulin-like growth factor binding protein (IGFBP) isoforms during bovine follicular development
}

\author{
B. Nicholas ${ }^{1,2}$, R. K. Scougall1,2, D. G. Armstrong² and R. Webb' \\ ${ }^{1}$ Division of Agricultural Sciences, School of Biosciences, University of Nottingham, Sutton \\ Bonington, Loughborough LE12 5RD, UK; and ${ }^{2}$ Department of Integrative Biology, Roslin \\ Institute (Edinburgh), Roslin, Midlothian EH25 9PS, UK
}

The insulin-like growth factor binding proteins (IGFBPs) bind IGFs with high affinity and so regulate their access to the type 1 and 2 IGF receptors. This is the principal mechanism involved in regulating IGF bioavailability during folliculogenesis. IGFBPs undergo a number of posttranslational modifications, including proteolytic cleavage, phosphorylation and glycosylation, which can regulate the affinity of IGFBPs for IGFs. However, the post-translational changes to IGFBPs that occur during folliculogenesis have not been fully characterized. The charge and size variants of the IGFBPs in bovine follicular fluid were examined by two-dimensional non-reducing SDS-PAGE followed by non-isotopic western ligand blot analysis, and immunoblot analysis during follicular development. The results demonstrate the presence of at least 51 IGFBP isoforms corresponding to IGFBP-1 to -6 in bovine follicular fluid from subordinate follicles, many of which were phosphorylated. The total number of IGFBPs was reduced in dominant follicles, whereas no gross changes in isoforms were observed during follicular development. These results demonstrate the high degree of conservation of IGFBP post-translational modifications between species, and from the in vitro dephosphorylation of these proteins it is hypothesized that these modifications may result in changes to IGF binding or susceptibility to proteolytic cleavage.

\section{Introduction}

The insulin-like growth factors (IGFs) are peptides that are structurally related to proinsulin and regulate cell differentiation, growth and survival (Bach and Rechler, 1995; Jones and Clemmons, 1995). The bioavailability of IGFs is regulated by a family of IGF binding proteins (IGFBPs) that bind IGFs with high affinity and so regulate their access to the type 1 and 2 IGF receptors through which their effects are mediated. The IGFBP family consists of six structurally related proteins (IGFBP-1-6) with high but different affinities for IGF-I and IGF-II (Shimasaki et al., 1991; Armstrong and Webb, 1999), as well as a number of IGFBP-related proteins with lower affinities for IGFs (Kim et al., 1997).

The affinity of IGFBPs for IGFs is regulated by a number of post-translational modifications, including phosphorylation, glycosylation and proteolytic cleavage (Firth, 1998). For example, phosphorylation of IGFBP-1 increases its affinity for IGFs (Jones et al., 1991; Coverley and Baxter, 1997) and proteolytic cleavage of IGFBPs generally results in reduced affinity of the fragments for IGFs (CwyfanHughes et al., 1997). The effects of glycosylation have been less well studied (LaTour et al., 1990; Cheung et al., 1991).

The IGF system has been well characterized during folliculogenesis (Armstrong et al., 1998, 2000; Spicer et al., 2001). In cattle and other species, including sheep (Monget et al., 1993; Armstrong et al., 1996; Besnard et al., 1996),

Email: benjamin.nicholas@nottingham.ac.uk
IGFBP profiles are altered during development, reflecting follicular status. In this regard, IGFBP-3 concentrations are essentially unchanged in dominant follicles when compared with healthy subordinate follicles; however, IGFBP-2, -4 and -5 concentrations are significantly lower in dominant follicles than in subordinate follicles (Monget et al., 1993; Cwyfan-Hughes et al., 1997; Armstrong et al., 1998; Mihm et al., 2000; Spicer et al., 2001). Conversely, it has been reported that IGFBP-4 and -5 concentrations are high in follicular fluid from atretic follicles (Monget et al., 1993). These changes in the steady-state concentration of IGFBPs in follicular fluid occur through a combination of changes in gene expression (Armstrong et al., 1998) and proteolysis (Rivera et al., 2001; Spicer et al., 2001).

The classical method by which IGFBP profiles have been examined has been by non-reducing one-dimensional SDSPAGE followed by western ligand blot analysis (Hossenlopp et al., 1986), although this procedure cannot detect the charge variants of the various IGFBPs. Thus, recent work has emphasized the advantage of two-dimensional nonreducing SDS-PAGE followed by western ligand blot analysis of IGFBP profiles in several species, including rats and humans (Chan and Nicoll, 1994; Weber et al., 1999).

With the exception of proteolytic degradation, limited information is available on the IGFBP post-translational modifications that occur during bovine follicular development. These changes could control the affinity of the IGFBPs for their ligand as well as regulating their susceptibility to proteolytic degradation and, hence, could potentially 
be key mechanisms in regulating IGF bioavailability during follicle growth.

As a first step toward analysing the role of IGFBP posttranslational modification in the control of follicle growth we have used two-dimensional SDS-PAGE to describe, for the first time, the various IGFBP size and charge variants present in follicular fluid from dominant and subordinate bovine ovarian follicles.

\section{Materials and Methods}

\section{Experimental animals}

The oestrous cycles of 20 Hereford $\times$ Holstein heifers were synchronized using two injections of a $\mathrm{PGF}_{2 \alpha}$ analogue (Estrumate; Schering Health Care Limited, Burgess Hill) at 12 day intervals. After the second injection, the animals were observed twice a day for signs of behavioural oestrus (oestrus $=$ day 0 ) and were killed on day 5 after oestrus.

\section{Materials}

The follicles were dissected and graded on the basis of size into groups of $<4 \mathrm{~mm}$ (subordinate) and $>8 \mathrm{~mm}$ (dominant) in diameter. These sizes were selected as both $4 \mathrm{~mm}$ and $8 \mathrm{~mm}$ are key stages in bovine follicular development (Webb et al., 1999). Follicular fluid was collected immediately by aspiration, centrifuged at $13000 \mathrm{~g}$ for $5 \mathrm{~min}$ and stored in aliquots at $-80^{\circ} \mathrm{C}$ until use. A protease inhibitor cocktail was added (Sigma P-2714; Sigma-Aldrich Company Ltd, Poole) to half of the samples before freezing.

Rabbit antisera raised against bovine IGFBP-2 and human IGFBP-4 were purchased from TCS Biologicals (Upstate Biotechnology, Lake Placid, NY). The antiserum against IGFBP-4 has been reported to have $50 \%$ crossreactivity with bovine IGFBP-2. PVDF membranes were obtained from Amersham Pharmacia Biotech (Little Chalfont), SDS molecular weight standards (Precision protein standards, Broad range) were purchased from Bio-Rad (Hemel Hempstead), extravidin-peroxidase, BSA (radioimmunoassay grade) and anti-rabbit peroxidase conjugate were obtained from Sigma. IGF-II was purchased from Gropep Pty Ltd (Adelaide) and D-biotinoyl-e-aminocaproic acid-N-hydroxysuccinimide ester (Biotin-7-NHS) was purchased from Boehringer-Mannheim (Mannheim).

\section{Preparation of biotinylated IGF-II}

Biotinylated IGF-II was prepared by diluting IGF-II $(50 \mu \mathrm{g})$ in $500 \mu \mathrm{l}$ PBS (pH 7.4). Biotin-7-NHS was dissolved in dimethylsulphoxide to a concentration of $20 \mathrm{mg} \mathrm{ml}^{-1}$; $10 \mu \mathrm{l}$ of this solution was added to the IGF-II solution and incubated for $2 \mathrm{~h}$ at room temperature with agitation. After the labelling reaction, free biotin ester was removed by PBS buffer exchange using centricon 3 microconcentrating units (Millipore (UK) Limited, Watford), concentrating to the dead-stop volume of $10 \mu \mathrm{l}$ three times. The final solution was made up in $200 \mu \mathrm{l}$ PBS and the labelled IGF-II was stored at $-80^{\circ} \mathrm{C}$ in $20 \mu \mathrm{l}$ aliquots.

\section{Non-reducing SDS-PAGE}

The procedure followed was a modification of that of Hossenlopp et al. (1986). Samples of follicular fluid $(0.75 \mu \mathrm{l})$ were diluted with $10 \mu \mathrm{l}$ of non-reducing sample

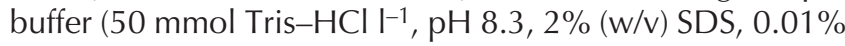
$(\mathrm{w} / \mathrm{v})$ bromophenol blue) and fractionated on $4 \%$ stacking $/ 12 \%$ resolving SDS-PAGE gels $(8.6 \mathrm{~cm} \times 6.8 \mathrm{~cm}$ Mini-Protean III system; Bio-Rad). The proteins were electroblotted on to a PVDF membrane for $1.5 \mathrm{~h}$ at room temperature (45 m per gel using an LKB Novablot semi-dry system and Towbin buffer) and were visualized by staining with $0.1 \%(\mathrm{w} / \mathrm{v})$ Ponceau red in $0.5 \%(\mathrm{v} / \mathrm{v})$ acetic acid.

\section{Non-reducing two-dimensional SDS-PAGE}

The procedure followed was a modification of that of Weber et al. (1999). Follicular fluid samples (125 $\mu \mathrm{g}$ protein per strip) were diluted in and made up to $185 \mu \mathrm{l}$ with rehydration buffer containing $8 \mathrm{~mol}$ urea $\mathrm{I}^{-1}, 0.2 \%(\mathrm{w} / \mathrm{v})$ Ampholine, pH 3-10 (Amersham Biosciences, Little Chalfont), and $1 \%(\mathrm{w} / \mathrm{v})$ CHAPS detergent. The prepared sample solutions were used to rehydrate $11 \mathrm{~cm}$ long BioRad Readystrip IPG (immobilized pH gradient) strips ( $\mathrm{pH}$ 3-10 linear) in a Bio-Rad isoelectric focussing/ rehydration cell at $50 \mathrm{~V}$ for $12 \mathrm{~h}$. Isoelectric focusing was performed in a Bio-Rad Protean IEF cell for a total of $35000 \mathrm{~V}$ hours at a maximum of $8000 \mathrm{~V}$ at $20^{\circ} \mathrm{C}$ by a preset programme according to the manufacturer's instructions. The gel strips were stored at $-80^{\circ} \mathrm{C}$ until use, when they were equilibrated for $15 \mathrm{~min}$ in $50 \mathrm{mmol}$ Tris- $\mathrm{HCl} \mathrm{I}^{-1}, \mathrm{pH}$ $8.3,6 \mathrm{~mol}^{-1} \mathrm{l}^{-1}, 30 \%(\mathrm{v} / \mathrm{v})$ glycerol, $2 \%(\mathrm{w} / \mathrm{v}) \mathrm{SDS}$ and a trace of bromophenol blue before overlay on $12 \%$ SDSPAGE gels $(13.3 \mathrm{~cm} \times 8.7 \mathrm{~cm}$ Criterion gel system; BioRad) in molten $1 \%(\mathrm{w} / \mathrm{v})$ SeaPlaque agarose in SDS-PAGE running buffer. The isoelectrically focused proteins were fractionated and electroblotted as described for the single dimension gels. Transfer of proteins was checked in each case by staining the membrane with Ponceau red solution.

\section{Total protein staining using biotinylation}

Non-reducing two-dimensional gels of bovine follicular fluid were electroblotted on to PVDF membrane as described previously and stained with Ponceau red to determine transfer efficiency. The Ponceau stain was removed by washing twice for $10 \mathrm{~min}$ with PBS $(\mathrm{pH} 7.4)$ containing $0.1 \%(\mathrm{v} / \mathrm{v})$ Tween 20 , followed by two washings with PBS. The membrane was incubated at room temperature $\left(18-24^{\circ} \mathrm{C}\right)$ with agitation in the presence of labelling solution (20 ml PBS containing $10 \mu \mathrm{l}$ of $20 \mathrm{mg}$ biotin-7$\mathrm{NHS} \mathrm{ml}{ }^{-1}$ ) for $1 \mathrm{~h}$. After the labelling reaction, the blot was washed three times with PBS-0.1\% (v/v) Tween 20 and blocked with 3\% (w/v) BSA in PBS-1.0\% (v/v) Tween 20 for $1 \mathrm{~h}$. The biotinylated proteins were detected using extravidinperoxidase (Sigma; 1 in 3000 dilution in blocking solution) 
at room temperature for $45 \mathrm{~min}$ and the membrane was washed three times for $5 \mathrm{~min}$ each with PBS-0.1\% (v/v) Tween 20. Horseradish peroxidase label was detected using ECL-plus kit (Amersham), with a typical exposure time of $30 \mathrm{~s}$.

\section{Western ligand blot}

The blotted membrane was rinsed twice with PBS- $0.1 \%$ $(\mathrm{v} / \mathrm{v})$ Tween 20 and blocked for $2 \mathrm{~h}$ at room temperature with $3 \%(\mathrm{w} / \mathrm{v})$ BSA in PBS-0.1\% (v/v) Tween 20 with agitation. The blocking solution was replaced with $15 \mathrm{ml}$ fresh blocking solution containing $2 \mu \mathrm{l}$ biotinylated IGF-II per minigel and the membrane was incubated overnight at $4^{\circ} \mathrm{C}$ with agitation. The next day the membrane was washed three times for 5 min each with PBS-0.1\% (v/v) Tween 20 and the solution was replaced with $20 \mathrm{ml}$ of a 1 in 4000 dilution of extravidin-peroxidase in blocking solution. The membrane was incubated with agitation for $2 \mathrm{~h}$ at room temperature and washed five times with PBS-0.1\% (v/v) Tween 20 before detection of signal using the ECL-plus system on hyperfilm-ECL film, and developed using an automated system (X-Ograph). Typical exposure times were between $10 \mathrm{~s}$ and $5 \mathrm{~min}$.

\section{Immunoblots}

PVDF membranes from two-dimensional separations of follicular fluid were probed for IGFBP-2 and -4 by first blocking in $3 \%(\mathrm{w} / \mathrm{v}) \mathrm{BSA}$ in PBS containing $0.1 \%(\mathrm{v} / \mathrm{v})$ Tween 20 for $1 \mathrm{~h}$ at room temperature. The blots were incubated overnight in blocking solution containing a 1 in 2000 dilution of either rabbit anti-bovine IGFBP-2 or rabbit anti-human IGFBP-4. The membranes were washed in PBS-0.1\% (v/v) Tween 20 and primary antibodies were detected using a 1 in 5000 dilution of goat anti-rabbit IgG peroxidase conjugate for $2 \mathrm{~h}$ at room temperature. Peroxidase signal was detected using the ECL-plus system.

\section{Phosphatase reaction}

Follicular fluid samples $(3 \mu \mathrm{l}(180 \mu \mathrm{g})$ per tube), snap frozen in liquid nitrogen without added protease inhibitor cocktail, were incubated in $5 \mu \mathrm{l}$ of $50 \mathrm{mmol}$ Tris- $\mathrm{HCl} \mathrm{I-1}$ (pH 7.4) for $3 \mathrm{~h}$ at $37^{\circ} \mathrm{C}$, containing $5 \mathrm{U}$ calf intestinal alkaline phosphatase (Promega, Madison, WI). The control tube contained no alkaline phosphatase.

On the next day, all samples were diluted in $185 \mu \mathrm{l}$ nonreducing two-dimensional rehydration buffer and analysed by two-dimensional SDS-PAGE as described previously.

\section{Results}

\section{One-dimensional western ligand blot analysis}

The results of a one-dimensional non-isotopic western ligand blot analysis performed on follicular fluid samples from four separate cows to be tested by two-dimensional SDS-PAGE are shown (Fig. 1). These results demonstrate

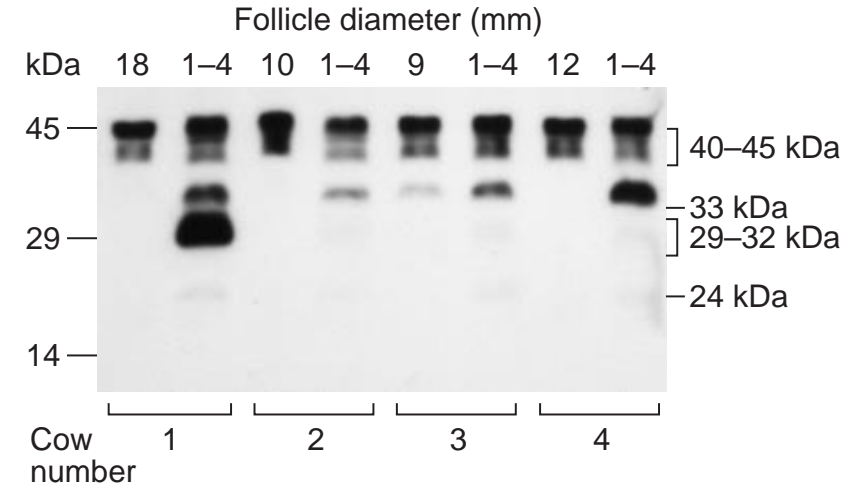

Fig. 1. One-dimensional western ligand blot analysis of bovine follicular fluid samples from four day 5 oestrous-synchronized cattle detected using biotinylated recombinant bovine insulin-like growth factor II (IGF-II). Follicular fluid samples collected in the presence of protease inhibitor from four dominant follicles $(9,10$, 12 and $18 \mathrm{~mm}$ in diameter) and pooled samples from four subordinate follicle populations (1-4 $\mathrm{mm}$ in diameter) are shown. Molecular masses $(\mathrm{kDa})$ are shown.

that the IGFBP profile alters depending on follicular developmental status. The dominant follicle $(>8 \mathrm{~mm}$ in diameter on day 5) contained only IGFBP-3, observed as a doublet of between $40 \mathrm{kDa}$ and $45 \mathrm{kDa}$, and occasionally a 33 kDa IGFBP (identified by immunoblot as IGFBP-2, results not shown). Pooled follicular fluid from small follicles from the same ovary $(<4 \mathrm{~mm}$ in diameter) contained IGFBPs with molecular masses of approximately 29 and $33 \mathrm{kDa}$, corresponding to IGFBP-4 (glycosylated form) and IGFBP-2, respectively. Occasionally an increase in an IGFBP species at a slightly higher molecular mass than the glycosylated form of IGFBP-4, which is known to contain IGFBP-5 (approximately $31 \mathrm{kDa}$ ) by western immunoblot, was observed in these small follicles; however, the size and irregularity of the band indicate that there may be an increase in other IGFBPs of similar molecular mass. Exposure times were very low (generally less than $5 \mathrm{~min}$ ) and background signals were limited, demonstrating that this non-isotopic method is ideally suited for western ligand blot analysis. The identities of IGFBP-2 and -4 were confirmed by immunoblot analysis (results not shown).

\section{Two-dimensional SDS-PAGE}

The two-dimensional analysis of IGFBP profiles was initially performed on a pooled follicular fluid sample from small ( $<4 \mathrm{~mm}$ in diameter) follicles, as this was likely to demonstrate all the major species present in bovine follicles. A representative total protein profile obtained after two-dimensional SDS-PAGE of pooled bovine follicular fluid from subordinate $(<4 \mathrm{~mm}$ ) follicles (cow number 2 in Fig. 1), in which comparatively few proteins were observed in the lower molecular mass region $(<50 \mathrm{kDa})$, is shown (Fig. 2a). The IGFBP western ligand blot profile of this follicular fluid sample, with a major doublet at 40-45 kDa 


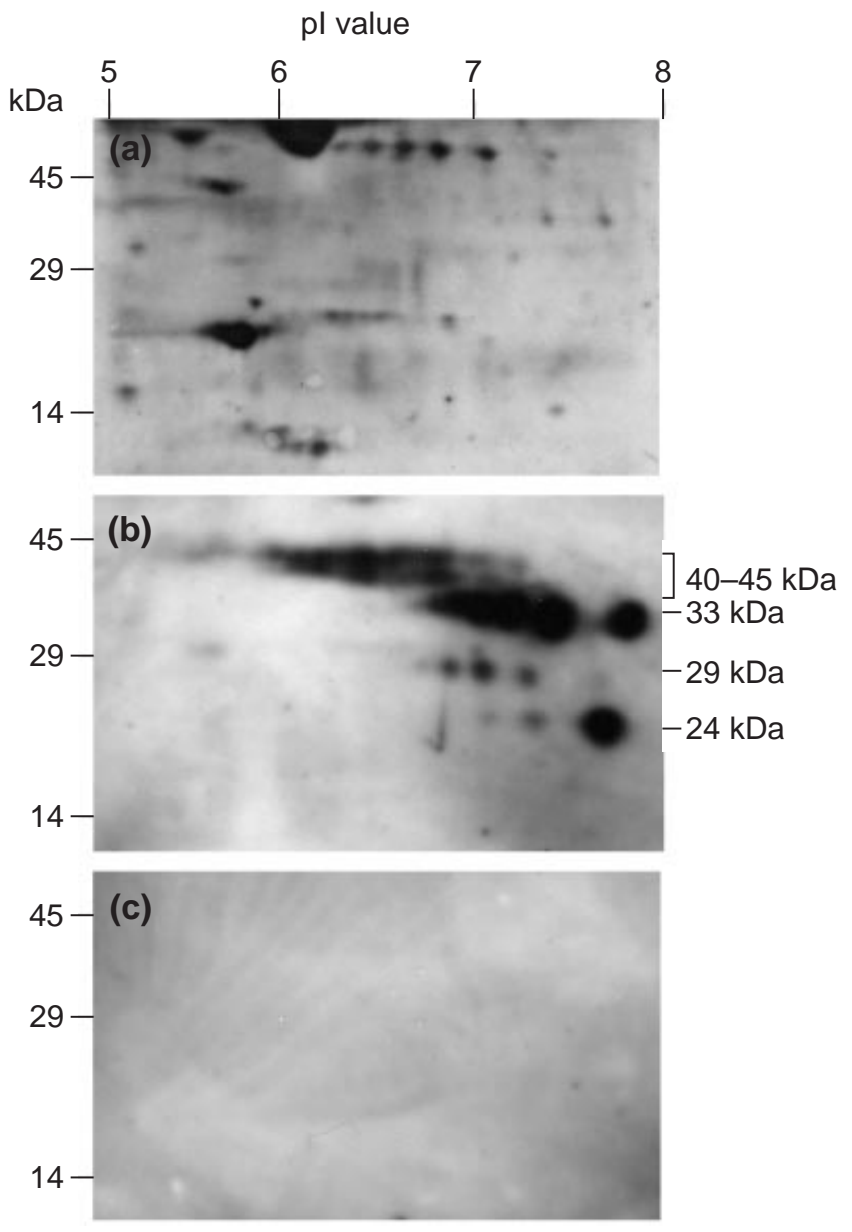

Fig. 2. Two-dimensional electrophoresis of bovine follicular fluid from a subordinate follicle (collected in the presence of protease inhibitor) from a pooled sample of $1-4 \mathrm{~mm}$ bovine follicles on day 5 after induced oestrus transferred on to PVDF membrane and stained either for (a) total protein or probed with biotin-labelled insulin-like growth factor II (IGF-II) in the (b) absence or (c) presence of excess unlabelled IGF-II. pl: isoelectric point. Molecular masses (kDa) are shown.

with a broad isoelectric point (pl) range, is shown (Fig. 2b). A second series of spots was observed at a molecular mass of $33 \mathrm{kDa}$; a third series was observed at $29 \mathrm{kDa}$ and a fourth series was observed at $24 \mathrm{kDa}$.

The detection of all the IGFBP spots was inhibited in the presence of an excess of unlabelled IGF-II, thereby demonstrating the specificity of this method for the detection of IGFBPs (Fig. 2C).

In duplicate blots to those used in Fig. 2, western immunoblot analysis was performed to confirm the identity of some of the spots observed by western ligand blot analysis (Fig. 3). IGFBP-2 was identified as the series of five major spots (and two fainter spots only visible after increased exposure of the film) occurring at approximately $33 \mathrm{kDa}$, between a pl value of 6.2 and 7.7 (Fig. 3a). IGFBP-4 was identified as a doublet of spots occurring at approximately 29 and $24 \mathrm{kDa}$ (Fig. 3b), with four spots visible at

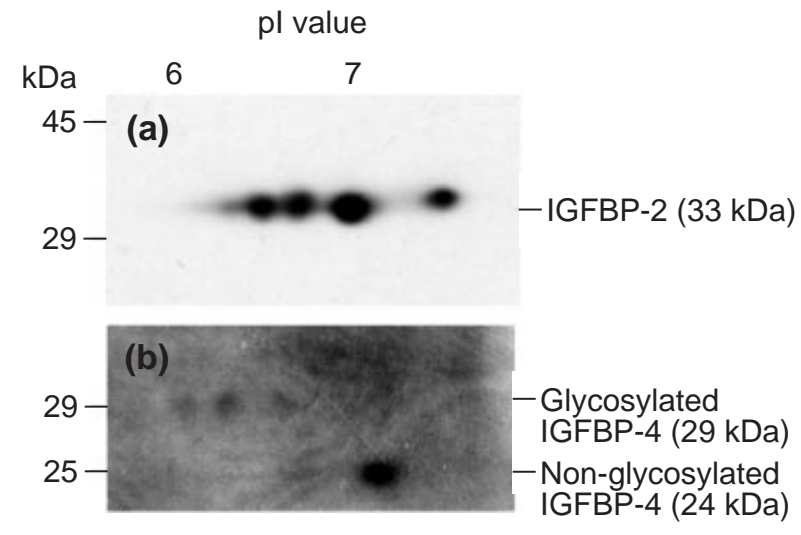

Fig. 3. Western blots of bovine follicular fluid (collected in the presence of protease inhibitors) from a pooled population of subordinate follicles (1-4 mm in diameter) on day 5 after induced oestrus, probed with (a) an insulin-like growth factor binding protein 2 (IGFBP-2) antibody and (b) an IGFBP-4 antibody. pl: isoelectric point. Molecular masses $(\mathrm{kDa})$ are shown.
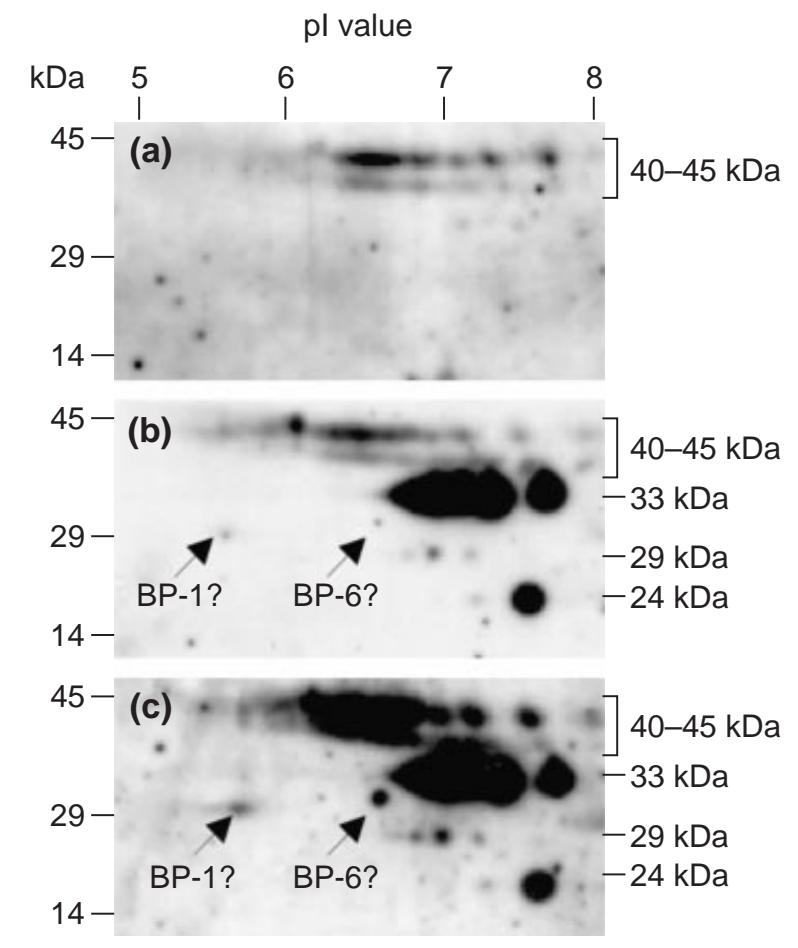

Fig. 4. Two-dimensional western ligand blots probed with biotinlabelled insulin-like growth factor II (IGF-II) of bovine follicular fluid samples on day 5 after induced oestrus (collected in the presence of protease inhibitors). Follicular fluid samples were collected from (a) a dominant follicle ( $>8 \mathrm{~mm}$ in diameter) and $(b, c)$ from two pools of subordinate $(1-4 \mathrm{~mm})$ follicles, the latter of which showed increased IGF-II binding at a 29-32 kDa band by one-dimensional western ligand blot analysis. pl: isoelectric point. Molecular masses $(\mathrm{kDa})$ are shown.

$29 \mathrm{kDa}$ ( $\mathrm{pl}$ value between 6.2 and 6.8), and three at $24 \mathrm{kDa}$ ( $\mathrm{pl}$ value between 6.4 and 7.4).

As a result of the lack of specific antibodies, the other IGFBP species were identified by molecular mass and 


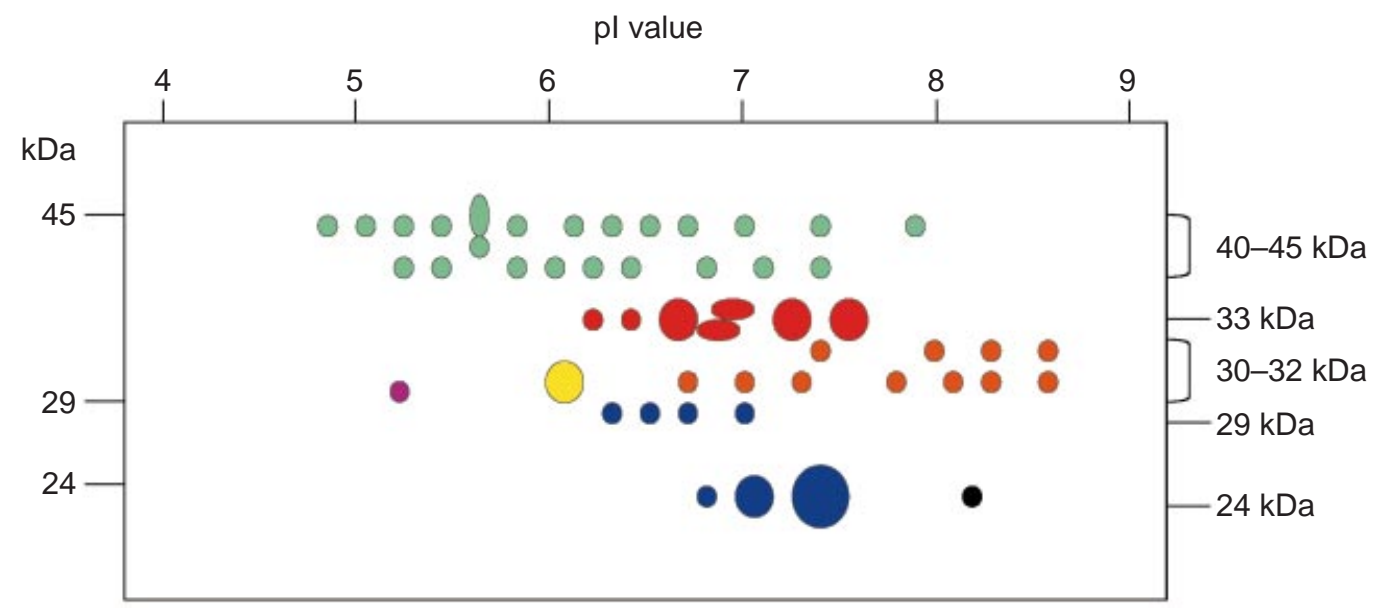

Fig. 5. Diagrammatic representation of the insulin-like growth factor binding protein (IGFBP) profiles detected in bovine follicular fluid samples by two-dimensional electrophoresis and western ligand blot analysis. These results represent the total number of spots identified from five oestrous-synchronized animals including dominant and pooled $1-4 \mathrm{~mm}$ subordinate follicle samples from each animal. Green: putative IGFBP-3; red: IGFBP-2; yellow: putative IGFBP-6; orange: putative IGFBP-5; blue: IGFBP-4; purple: IGFBP-1; black: unknown.

patterns from two-dimensional western ligand blots from five different animals (representative examples can be seen in Figs 2 and 4). For example, IGFBP-3 with a molecular mass of 40 and $44 \mathrm{kDa}$ had a pl value of between 5.3 and 7.9, and 4.9 and 7.9, respectively. It was observed that in the samples which contained increased IGF-II binding to a band at the $31 \mathrm{kDa}$ region by one-dimensional western ligand blot analysis (Fig. 1; subordinate follicle from cow 1 ), several extra sets of spots occurred about the $31 \mathrm{kDa}$ region (Fig. 4c); however, these spots occurred in distinct pl value regions. For example, the spot tentatively identified as IGFBP-1, with a molecular mass of approximately $31 \mathrm{kDa}$, had a pl value of approximately 5.3, which was only faintly visible in most cases, whereas another of a similar molecular mass was observed at a pl value of 6.1, in a similar pl value and molecular mass position to that of human IGFBP-6. Furthermore, a series of spots between $30 \mathrm{kDa}$ and $32 \mathrm{kDa}$ and at a pl value of 6.6-8.6 and 7.5-8.6 was observed in a very similar molecular mass and pl value distribution to that of human IGFBP-5, although this identification could not be confirmed by immunoblotting.

A diagrammatic map of the occurrence of each IGFBP species was constructed using the results from five individual pairs of dominant and subordinate follicular fluid samples to map the position of each IGFBP species (Fig. 5), and a summary of $\mathrm{pl}$ value ranges for IGFBPs observed consistently at each molecular mass is shown (Table 1).

\section{Phosphatase treatment}

Removal of phosphorylated sites by alkaline phosphatase treatment resulted in the loss of almost all IGFBP spots detected by ligand blot analysis (Fig. 6b) when compared with controls (Fig. 6a), although single spots at $43 \mathrm{kDa}$ (pl value 6.1), $41 \mathrm{kDa}$ (pl value 6.0) $33 \mathrm{kDa}$ (pl value 6.5) and
Table 1. Molecular mass and pl values for each insulin-like growth factor binding protein (IGFBP) isoform detected in bovine follicular fluid

\begin{tabular}{lccc}
\hline IGFBP & $\begin{array}{c}\text { Molecular mass } \\
(\mathrm{kDa})\end{array}$ & $\begin{array}{c}\text { Number of } \\
\text { charge variants }\end{array}$ & $\begin{array}{c}\text { pl value } \\
\text { range }\end{array}$ \\
\hline Putative IGFBP-3 & 44 & 13 & $4.9-7.9$ \\
Putative IGFBP-3 & 40 & 10 & $5.3-7.9$ \\
IGFBP-2 & 33 & 7 & $6.2-7.7$ \\
Putative IGFBP-6 & 32 & 1 & 6.1 \\
Putative IGFBP-5 & 31 & 4 & $7.5-8.6$ \\
Putative IGFBP-5 & 30 & 7 & $6.6-8.6$ \\
Putative IGFBP-1 & 30 & 1 & 5.3 \\
IGFBP-4 & 29 & 4 & $6.2-6.8$ \\
IGFBP-4 & 24 & 3 & $6.4-7.4$ \\
Unknown & 24 & 1 & 8.2 \\
\hline
\end{tabular}

pl: isoelectric point.

$24 \mathrm{kDa}$ (pl value 7.2) were visible, probably representing the dephosphorylated forms of IGFBP-3, IGFBP-2 and nonglycosylated IGFBP-4, respectively. Protein loadings for these gels were increased to maximize detection of the faint spots in the phosphatase-treated samples, resulting in overloading of the control samples.

\section{Developmental changes in IGFBP profiles}

Follicular fluid from dominant ( $>8 \mathrm{~mm}$ in diameter) follicles contained only IGFBP-3 (Fig. 4a), whereas in the subordinate follicles $(<4 \mathrm{~mm}$ in diameter), IGFBP-2, -3 and -4 were detected (Fig. 4b). In the follicular fluid samples of subordinate follicles that contained increased bands on one-dimensional western ligand blot analysis at 29-31 kDa, extra spots were detected which corresponded to the 


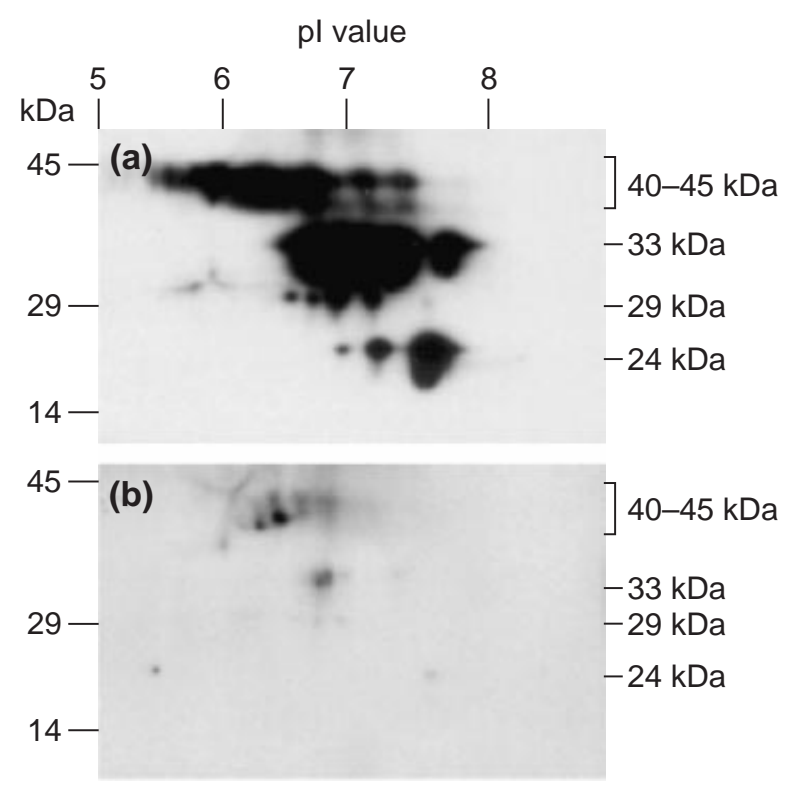

Fig. 6. Representative two-dimensional western ligand blots probed with biotin-labelled insulin-like growth factor II (IGF-II) of follicular fluid samples pooled from 1-4 mm subordinate bovine follicles (without protease inhibitors) on day 5 after induced oestrus, incubated in the (a) absence or (b) presence of calf intestinal alkaline phosphatase (control sample contained buffer only). The results shown are typical of three individual experiments. pl: isoelectric point. Molecular masses (kDa) are shown.

expected molecular masses and pl values for IGFBP-6 and IGFBP-1 (Fig. 4c), as observed for human IGFBP isoforms. Spots in the pl value and molecular mass region corresponding to human IGFBP-5 and an unknown spot at $24 \mathrm{kDa}$ ( $\mathrm{pl}$ value 8.2 ) were only faintly visible on these blots; however, they were clearly visible after prolonged exposure of the film to the chemiluminescent signal.

No obvious differences in the post-translational modification of IGFBP-3 were observed between small and large follicles.

\section{Discussion}

In the present study the first analysis of IGFBPs in bovine follicular fluid by two-dimensional SDS-PAGE is presented. The charge and size variants of individual IGFBPs present during the final stages of follicle development in both dominant and subordinate follicles are described - information that is not available when conventional one-dimensional ligand blot analysis is performed. The results also confirm the efficacy of the non-radioactive western ligand blot method used in these studies, which gave reliable ligand blot results with low exposure times (typically less than $1 \mathrm{~min}$.

Two-dimensional analysis revealed an array of at least 51 spots corresponding to binding proteins, many of which are seen in other species, but other spots that appear to be novel. Although there are few publications on the expected binding protein arrays, the pattern obtained was similar to that observed in rat (Chan and Nicoll, 1994) and human (Weber et al., 1999) serum binding protein arrays. However, the method of analysis was different in each case and for the first time a two-dimensional western ligand blot procedure is described that combines the use of immobilized IEF strips with non-isotopic western ligand blot detection.

The binding protein spots detected using biotinylated IGF-II were completely removed in the presence of saturating concentrations of unlabelled IGF-II, indicating that all the spots detected were indeed genuine IGFBPs. The proteins detected by this method were different in dominant compared with subordinate follicles and corresponded to the changes observed using conventional one-dimensional western ligand blot analysis, which aided the identification of the spots on the two-dimensional gels.

The analysis of bovine follicular fluid samples by onedimensional SDS-PAGE, followed by western ligand blot analysis, has revealed an IGFBP array essentially the same as that shown previously in sheep (Armstrong et al., 1996), humans (Cataldo and Giudice, 1992) and cows (Mihm et al., 2000), with the loss of low molecular mass species during selection of the dominant follicle. In some subordinate follicles there was an increase in intensity at a band at 29-32 kDa (cow number 1 subordinate follicle). This band was in fact irregular in shape and may have been due to changes in IGFBPs of slightly higher molecular mass; however, this contention could not be resolved by conventional analysis, but it was confirmed by western immunoblot analysis that this band contained IGFBP-5 (molecular mass $=31 \mathrm{kDa}$, results not shown), an IGFBP that is thought to be upregulated during follicular atresia (Monget et al., 1993).

As observed by one-dimensional analysis, IGFBP-3 was present in follicular fluid from dominant and subordinate follicles, and was present as a doublet of multiple spots at two molecular masses, probably due to changes in glycosylation states. A number of charge variants for each of the size isoforms was present, which covered a wide range of $\mathrm{pl}$ values. In total, 23 different size and charge variants of IGFBP-3 were identified.

IGFBP-2 was observed only in follicular fluid from subordinate follicles and was positively identified using an antiIGFBP-2 antibody. Six IGFBP-2 isoforms were detected in both western ligand and immunoblots that differed in charge but not molecular mass, indicating that this protein is not glycosylated, and thereby confirming the results of other studies (Chan and Nicoll, 1994). However, the existence of a seventh isoform as a pl value doublet at two slightly different molecular masses indicates that there may be other post-translational modifications that have not yet been described.

IGFBP-4 was detected in both ligand and immunoblots as two arrays of spots at 29 and $24 \mathrm{kDa}$. Immunoblot analysis proved difficult as the antibodies used were raised against the human protein and had low crossreactivity with 
the bovine binding proteins. However, four charge variants of the glycosylated IGFBP-4 isoform and three charge variants of the non-glycosylated isoform were detected. A fourth faint spot at $24 \mathrm{kDa}$ was observed using the western ligand blot analysis that may have been a further IGFBP-4 isoform; however, this spot was not observed when using the antibody, possibly due to the low quantity of this isoform, although it could also be a degradation product of another IGFBP. These protein arrays were almost identical to those identified in other species; however, a greater number of spots was observed than reported in other studies, with an increase in the number of charge variants for the glycosylated form of IGFBP-4 (an extra spot visible at approximately pl value 6.8 ) and an increase in the number of spots for IGFBP-2 (extra spot visible at pl value 6.2 and doublet at pl value 7.0).

Analysis of follicular fluid demonstrated increased IGFBP-4 concentrations in some samples. It also demonstrated the presence of other binding proteins at a slightly higher molecular mass, which may be due to the presence of IGFBP-1, -5 and -6 , although no antibody is currently available for these IGFBPs in cattle. The molecular masses and $\mathrm{pl}$ values of the detected spots correspond to the expected size and $\mathrm{pl}$ values of these lower molecular mass binding proteins as determined in humans and rats (Chan and Nicoll, 1994; Weber et al., 1999). Although the molecular masses of IGFBP-1, -2, -5 and -6 and glycosylated IGFBP-4 are similar (29-32 kDa), their wide range of $\mathrm{pl}$ values enables the precise resolution of these proteins, and the use of larger gels may help to characterize them even further. IGFBP-1 and -6 have not previously been observed in bovine follicular fluid samples. This may be due to very low expression or these isoforms may not be synthesized within the follicle compartment, entering instead as a result of changes in basal membrane leakage due to the onset of atresia. As their expression appears to be associated with follicular atresia, which occurs in only selected subordinate follicles at any one time, the expression of mRNA for IGFBP-1 and -6 may have been overlooked.

The phosphorylation state of IGFBPs was analysed using alkaline phosphatase. Treatment of follicular fluid resulted in the loss of all pl value arrays and the appearance of single spots at molecular masses of $33 \mathrm{kDa}$ (pl value 6.7), $29 \mathrm{kDa}$ (pl value 6.5 ) and $24 \mathrm{kDa}$ (pl value 7.1), corresponding to IGFBP-2 and the glycosylated and non-glycosylated forms of IGFBP-4, respectively. The lack of detection of the expected IGFBP-3 doublet at a pl value of 4.9-7.9 may have been due to changes in IGF binding capability after dephosphorylation or to increased susceptibility to proteolytic cleavage. Seven IGFBP-2 charge variants were identified in the present study and all except one (the fully dephosphorylated form) were deleted after alkaline phosphatase treatment, indicating that all the potential phosphorylation sites are phosphorylated in IGFBP-2 in follicular fluid.

The significance of these post-translational modifications on the structure and function of the IGFBPs remains unknown, although phosphorylation of IGFBP-1 alters IGF binding capability (Jones et al., 1991; Webb et al., 1999). These modifications may also have implications for the susceptibility of these proteins to proteolysis, which is one way in which IGF bioavailability may be altered. The detection of the same number of charge variants in either IGFBP-2 or IGFBP-4 immunoblots as in the ligand blots indicates that these modifications do not alter IGF binding capacity. In the future it may be possible to identify and purify each of the different isoforms of the binding proteins and to assess their differing biological activities.

In conclusion, we have demonstrated two-dimensional IGFBP profiles using a novel non-radioactive western ligand blot method, which has shown the presence of a greater number of IGFBP-2 and -4 isoforms than previous methods have detected in either human or rat serum. However, there has been a remarkable conservation in the general pattern of post-translational modification of the IGFBPs between species, which may indicate that the biological effect of these modifications is essential to the bioactivity of the IGFBPs.

This work was supported by the BBSRC.

\section{References}

Armstrong DG, Hogg CO, Campbell BK and Webb R (1996) Insulin-like growth factor (IGF)-binding protein production by primary cultures of ovine granulosa and theca cells: the effects of IGF-I, gonadotropin, and follicle size Biology of Reproduction 55 1163-1171

Armstrong DG, Baxter G, Gutierrez CG, Hogg CO, Glazyrin AL, Campbell BK, Bramley TA and Webb R (1998) Insulin-like growth factor binding protein -2 and -4 messenger ribonucleic acid expression in bovine ovarian follicles: effect of gonadotropins and developmental status Endocrinology 139 2146-2154

Armstrong DG, Gutierrez CG, Baxter G, Glazyrin AL, Mann GE, Woad KJ, Hogg CO and Webb R (2000) Expression of mRNA encoding IGF-I, IGFII and type 1 IGF receptor in bovine ovarian follicles Journal of Endocrinology 165 101-113

Bach LA and Rechler MM (1995) Insulin-like growth factor binding proteins Diabetes Reviews 3 38-61

Besnard N, Pisselet C, Monniaux D, Locatelli A, Benne F, Gasser F, Hatey F and Monget $\mathbf{P}$ (1996) Expression of messenger ribonucleic acids of insulin-like growth factor binding protein-2, -4 and -5 in the ovine ovary: localization and changes during growth and atresia of antral follicles Biology of Reproduction 55 1356-1367

Cataldo NA and Giudice LC (1992) Insulin-like growth factor binding profiles in human ovarian follicular fluid correlate with follicular functional status Journal of Clinical Endocrinology and Metabolism $\mathbf{7 4}$ 821-829

Chan KC and Nicoll CS (1994) Characterization of rat serum insulin-like growth factor-binding proteins by two-dimensional gel electrophoresis: identification of a potentially novel form Endocrinology 134 2574-2580

Cheung PT, Smith EP, Shimasaki S, Ling N and Chernausek SD (1991) Characterization of an insulin-like growth factor binding protein (IGFBP4) produced by the B104 rat neuronal cell line: chemical and biological properties and differential synthesis by sublines Endocrinology 129 1006-1015

Coverley JA and Baxter RC (1997) Phosphorylation of insulin-like growth factor binding proteins Molecular and Cellular Immunology 128 1-5

Cwyfan-Hughes SC, Mason HD, Franks S and Holly JM (1997) Modulation of the IGFBPs by follicle size in the human ovary Journal of Endocrinology 154 35-43

Firth SM (1998) Methods to detect and analyze modified insulin-like growth factor binding proteins. In Molecular Mechanisms to Regulate the 
Activities of Insulin-Like Growth Factors pp 79-87 Eds K Takan et al. Elsevier, Amsterdam

Hossenlopp P, Seurin KD, Segovia-Quinson B, Hardouin S and Binoux M (1986) Analysis of serum insulin-like growth factor binding proteins using western blotting: use of the method for titration of the binding proteins and competitive binding studies Analytical Biochemistry 154 138-143

Jones JI and Clemmons DR (1995) Insulin-like growth factors and their binding proteins: biological actions Endocrine Reviews 16 3-34

Jones JL, D'Ercole AJ, Camacho-Hubner C and Clemmons DR (1991) Phosphorylation of insulin-like growth factor (IGF)-binding protein 1 in cell culture and in vivo: effects on affinity for IGF-I Proceedings National Academy of Sciences USA 88 7481-7485

Kim HS, Nagalla SR, Oh Y, Wilson E, Roberts CT, Jr and Rosenfeld RG (1997) Identification of a family of low affinity insulin-like growth factor binding proteins (IGFBPs): characterization of connective tissue growth factor as a member of the IGFBP superfamily Proceedings National Academy of Sciences USA 9412 981-12 986

LaTour D, Nohan S, Linkhart TA, Baylink DJ and Strong DD (1990) Inhibitory insulin-like growth factor binding protein: cloning, complete sequence, and physiological regulation Molecular Endocrinology 4 1806-1814

Mihm M, Austin EJ, Good TEM, Ireland JLH, Knight PG, Roche JF and Ireland JJ (2000) Identification of potential intrafollicular factors involved in selection of dominant follicles in heifers Biology of Reproduction 63 811-819

Monget P, Monniaux D, Pisselet C and Durand P (1993) Changes in insulinlike growth factor-I (IGF-I), IGF-II and their binding proteins during growth and atresia of ovine ovarian follicles Endocrinology 132 1438-1446

Rivera GM, Chandrasekher YA, Evans ACO, Giudice LC and Fortune JE (2001) A potential role for insulin-like growth factor binding protein-4 proteolysis in the establishment of ovarian follicular dominance in cattle Biology of Reproduction 65 102-111

Shimasaki S, Gao L, Shimonaka M and Ling N (1991) Isolation and molecular cloning of insulin-like growth factor-binding protein-4 Molecular Endocrinology 5 938-942

Spicer LJ, Chamberlain CS and Morgan GL (2001) Proteolytic activity degrading insulin-like growth factor-binding protein (IGFBP)-4 and -5 but not IGFBP-2 and - 3 in preovulatory bovine follicles Domestic Animal Endocrinology 21 1-15

Webb R, Campbell BK, Garverick HA, Gong JG, Gutierrez CG and Armstrong DG (1999) Molecular mechanisms regulating follicular recruitment and selection Journal of Reproduction and Fertility Supplement 54 33-48

Weber MM, Spottl G, GossI C and Engelhardt D (1999) Characterization of human insulin-like growth factor binding proteins by two-dimensional polyacrylamide gel electrophoresis and western ligand blot analysis Journal of Clinical Endocrinology and Metabolism 84 1679-1684

Received 18 December 2001.

First decision 22 February 2002.

Revised manuscript received 21 May 2002.

Accepted 10 June 2002. 